\title{
PENERAPAN METODE PEMBELAJARAN ROLE PLAYING DALAM MENINGKATKAN HASIL BELAJAR IPS SISWA KELAS VIII.D SMP NEGERI 40 PEKANBARU TAHUN 2017
}

\author{
Hidayati Hidayati, Imrialdi \\ SMP Negeri 40 Pekanbaru \\ hidayati@email.com
}

\begin{abstract}
In SMP 40 Pekanbaru, many problems of students in the learning process IPS caused by external factor as the influence of friends environment and internal factors as learning approaches, methods, media or learning tools are used. These problems must be repaired because in addition to results in student learning outcomes that are still below the Minimum Completeness Criteria (KKM), the learning of Social Sciences (IPS) also has a central role in the intellectual development of social, emotional students and is a supporting success in studying of the other fields of study. The reseacrh was designed with the class action research by the Kemmis and McTaggart models in the form of spiral cycles. The results showed that the application of role palying learning methods have improved IPS learning outcomes of VIII.D graders at SMP 40 Pekanbaru in the years of 2017th with an average value class and the percentage of KKM achievment during the pre actions was 69.3 and $36 \%$, in the cycle I was 78.6 and $69 \%$, and in the cycle II it became 85.1 and $95 \%$.
\end{abstract}

Key Words: Role Playing Learning Methods, IPS Learning Outcomes

\section{PENDAHULUAN}

Pendidikan merupakan usaha sadar dan terencana untuk mewujudkan suasana belajar dan proses pembelajaran agar peserta didik secara aktif dapat mengembangkan potensi dirinya untuk memiliki kekuatan spiritual keagamaan, pengendalian diri, kepribadian, kecerdasan, akhlak mulia, serta keterampilan yang diperlukan dirinya dan masyarakat. Melalui pendidikan, suatu bangsa dapat meningkatkan kualitas sumber daya manusia yang tangguh, mandiri, berkarakter dan berdaya saing.

Sekolah sebagai lembaga pendidikan memiliki tugas dan tanggung jawab penuh dalam menjalankan amanat pendidikan. Sekolah merupakan suatu institusi yang dirancang untuk membawa siswa pada proses belajar, di bawah pengawasan guru atau tenaga pendidik profesional. Proses pembelajaran diselenggarakan dengan tujuan agar siswa mencapai pemahaman yang optimal

Hidayati, Penerapan Metode Pembelajaran Role Playing Dalam Meningkatkan Hasil Belajar IPS Siswa Kelas VIII.D SMP Negeri 40 Pekanbaru Tahun 2017 
terhadap materi yang diajarkan. Pembelajaran yang berhasil ditunjukkan adanya perubahan sikap pada diri siswa dan dikuasainya materi pembelajaran sesuai dengan indikator yang telah ditetapkan oleh guru dalam rencana pembelajaran. Sebagai seorang pendidik, guru tentunya selalu berusaha dan berharap agar peserta didiknya selalu mengikuti pembelajaran dengan baik, sehingga kompetensi yang diharapkan dapat tercapai. Keadaan tersebut dapat juga dikatakan bahwa seorang pendidik berusaha dan mengharapkan minat belajar peserta didik dapat meningkat.

Salah satu dari mata pelajaran yang dipelajari di SMP adalah IImu Pengetahuan Sosial (IPS). IPS merupakan mata pelajaran yang mengkaji tentang lingkungan serta kehidupan sosial yang terdapat dalam kehidupan sehari-hari. Mata pelajaran IPS memuat materi Geografi, Sejarah, Sosiologi dan Ekonomi. Melalui mata pelajaran IPS, siswa disiapkan dan diarahkan agar mampu menjadi warga negara yang demokratis dan bertanggung jawab serta warga dunia yang cinta damai.

Dalam upaya meningkatkan kualitas pembelajaran, guru menggunakan beberapa metode yang bervariasi. Pemilihan berbagai metode pembelajaran harus dipertimbangkan sebelum digunakan. Pendekatan kooperatif merupakan salah satu metode pembelajaran yang akhir-akhir ini sering digunakan. Pendekatan ini lebih menekankan kerja sama antar siswa. Kelas dibagi menjadi kelompok-kelompok belajar yang terdiri dari siswa-siswa yang bekerja sama dalam satu perencanaan kegiatan mengajar. Setiap anggota kelompok diharapkan dapat saling bekerja sama secara sportif satu sama lain dan bertanggung jawab baik kepada dirinya sendiri maupun pada anggota dalam satu kelompok.

SMP Negeri 40 Pekanbaru merupakan salah satu SMP negeri yang berada dipinggiran kota Pekanbaru. Di SMP Negeri 40 Pekanbaru, terdapat berbagai masalah yang dihadapi siswa dalam proses pembelajaran diantaranya; kurangnya motivasi belajar siswa, kurang aktifnya siswa dalam kegiatan pembelajaran, siswa sulit menguasi materi dan rendahnya kemampuan dasar IPS siswa sehingga membuat hasil belajar siswa rendah. Selain itu, sekitar 50\% siswa belum mencapai Kriteria Ketuntasan Minimal (KKM) yang ditetapkan sekolah pada mata pelajaran IPS, yaitu 80 . 
Paling tidak, ada dua macam faktor yang menyebabkan rendahnya tingkat minat dan kemampuan dalam mengikuti pembelajaran yaitu faktor eksternal dan faktor internal. Yang termasuk faktor eksternal, di antaranya pengaruh lingkungan, yakni lingkungan dalam kelas yang melihat tingkah laku dari temannya dan dari keluarga yang kurang memperhatikan kemajuan belajar siswa. Akibatnya, siswa terbiasa untuk melakukan kegiatan yang menurut dia benar. Sedangkan faktor internalnya meliputi, pendekatan pembelajaran, metode, media, atau sumber pembelajaran.

Jika kondisi pembelajaran semacam itu dibiarkan berlarut-larut, bukan tidak mungkin kemampuan aktifitas pembelajaran dikalangan siswa akan terus berada pada tataran yang rendah. Para siswa akan terus-menerus mengalami kesulitan dalam mengekspresikan kemampuan dan minatnya. Masalah tersebut perlu segera diatasi karena selain berakibat pada hasil belajar siswa yang masih dibawah KKM, pembelajaran IPS memiliki peran sentral dalam perkembangan intelektual sosial, emosional peserta didik dan merupakan penunjang keberhasilan dalam mempelajari bidang studi lainnya.

Terkait dengan kondisi tersebut, maka dilaksanakan penelitian tindakan kelas dengan menerapkan metode pembelajaran yang dapat meningkatkan hasil belajar IPS siswa di kelas VIII.D SMP Negeri 40 Pekanbaru yaitu metode pembelajaran Role Playing.

\section{METODE PENELITIAN}

Penelitian dilaksanakan di SMP Negeri 40 Pekanbaru pada bulan Februari hingga bulan April 2017 dengan subjek penelitian yaitu siswa-siswi kelas VIII.D SMP Negeri 40 Pekanbaru tahun ajaran 2016/2017 yang berjumlah 42 orang. Penelitian yang dilakukan adalah penelitian tindakan kelas dengan model Kemmis dan Mc Taggart berupa siklus yang dilakukan secara berulang dan berkelanjutan (siklus spiral). Pelaksanaan penelitian terdiri dari dua sikus yaitu siklus I dan silus II dengan tahapan; 1) Perancangan, 2) Pelaksanaan, 3) Observasi, dan 4) Refleksi. Dalam setiap siklus, terdiri dari 3 pertemuan dan setiap pertemuannya berlangsung selama 2 jam pelajaran. Adapun instrumen 
penelitian yang digunakan oleh peneliti dalam mengumpulkan data meliputi tes tertulis berupa soal essay yang diujikan pada awal dan akhir siklus serta lembar observasi terhadap aktivitas guru dan siswa saat pelaksaan tindakan. Data yang telah dikumpulkan kemudian dianilisis dengan teknik tertentu yang dilakukan terhadap hasil tes tertulis pada saat pra tindakan, siklus I dan siklus II dengan menggunakan rumusan rata-rata (mean) melalui persamaan:

$$
\mathrm{M}=\frac{\Sigma \mathrm{X}}{\mathrm{N}}
$$

Keterangan:

$M \quad=$ Rata-rata (mean)

$\Sigma \mathrm{X}=$ Jumlah nilai

$\mathrm{N}=$ Jumlah siswa

Keberhasilan pelaksanaan pembelajaran dianalisis setelah menghitung persentasenya dengan persamaan:

$$
\mathrm{P}=\frac{\mathrm{F}}{\mathrm{N}} \times 100 \%
$$

Keterangan:

$\mathrm{P} \quad=$ Angka persentase

$\mathrm{F} \quad=$ Jumlah siswa yang mencapai nilai $\geq \mathrm{KKM}$

$\mathrm{N}$ = Banyaknya jumlah subjek penelitian

Indikator keberhasilan penelitian ditandai dengan adanya peningkatan hasil belajar berupa peningkatan hasil tes tertulis pada saat pra tindakan, siklus I dan siklus II serta sebanyak $80 \%$ dari jumlah siswa yang mengikuti proses pembelajaran telah mencapai nilai KKM, yaitu 80 .

\section{HASIL PENELITIAN DAN PEMBAHASAN}

\section{Kondisi Awal (Pra Tindakan)}

Hasil pengamatan awal sebelum tindakan menunjukkan bahwa pembelajaran berpusat pada guru, siswa terlihat pasif selama pembelajaran, sebagian siswa perhatiannya tidak terfokus pada pembelajaran, guru cenderung menggunakan metode ekspositori dan lebih menekankan pada penguasaan materi daripada proses belajar. Siswa diberikan penjelasan 
singkat tentang sebuah materi, kemudian diminta mengerjakan soal. Guru memang memberikan bimbingan saat pengerjaan, tapi karena belum jelas saat penyampaian materi, banyak timbul pertanyaan yang menyebabkan pembelajaran tidak efektif karena guru harus mengulang setiap materi langsung kepada setiap siswa yang bertanya saat memberikan bimbingan.

Hasil analisis tes menunjukkan bahwa nilai rata-rata kelas 69,3 dengan nilai tertinggi 80 dan nilai terendah 50 . Adapun nilai yang diperoleh siswa pada pra tindakan dapat disajikan dalam Tabel. 1.

\section{Tabel 1}

Nilai Siswa Pra Tindakan

\begin{tabular}{|c|l|c|c|}
\hline No & \multicolumn{1}{|c|}{ Kategori } & Jumlah & $(\%)$ \\
\hline 1 & Siswa yang tuntas & 15 & 36 \\
\hline 2 & Siswa yang tidak tuntas & 27 & 64 \\
\hline 3 & Rata-rata nilai & 69,3 \\
\hline 4 & Ketuntasan kelompok & \multicolumn{2}{|c|}{$36 \%$} \\
\hline
\end{tabular}

\section{Siklus I}

Data yang diperoleh pada pra tindakan dijadikan sebagai acuan dalam pelaksanaan tindakan pada siklus I yang meliputi kegiatan:

Perencanaan

Peneliti menyusun rencana tindakan sebagai berikut: (1) menentukan waktu pelaksanaan, (2) menentukan materi sesuai dengan Kompetensi Dasar, (3) menyusun Rencana Pelaksanaan Pembelajaran (RPP) sesuai dengan indikator, (4) menyusun lembar kerja siswa dan soal evaluasi, (5) menyusun pedoman penilaian, (6) menyusun lembar observasi, (7) menyiapkan sumber belajar dan metode pembelajaran.

Pelaksanaan

Pelaksanaan penelitian siklus I dilaksanakan dalam tiga pertemuan, dengan tema kesehatan. Pembelajaran menggunakan metode pembelajaran role playing. Adapun nilai yang diperoleh siswa pada pra tindakan dapat disajikan dalam Tabel. 2. 


\section{Tabel 2}

Nilai Siswa Siklus I

\begin{tabular}{|c|l|c|c|}
\hline No & \multicolumn{1}{|c|}{ Kategori } & Jumlah & $(\%)$ \\
\hline 1 & Siswa yang tuntas & 29 & 69 \\
\hline 2 & Siswa yang tidak tuntas & 13 & 31 \\
\hline 3 & Rata-rata nilai & \multicolumn{2}{|c|}{78,6} \\
\hline 4 & Ketuntasan kelompok & \multicolumn{2}{|c|}{$69 \%$} \\
\hline
\end{tabular}

\section{Observasi}

Hasil pengamatan pembelajaran pada siklus I diperoleh bahwa siswa lebih antusias mengikuti pembelajaran karena permainan yang disajikan menurut mereka menarik. Keinginan belajar siswa semakin kuat, karena siswa ingin tahu bagaimana cara dan pelaksanaannya dalam kelompok. Pada saat menentukan permasalahan dan aturan permainan, siswa belum ikut berpartisipasi aktif. Saat guru mengajukan pertanyaan hanya beberapa anak saja yang mau merespon.

Pada saat permainan suasana kelas menjadi gaduh, sehingga mengganggu kelas yang lain. Pembelajaran menggunakan metode role playing ternyata membutuhkan waktu yang lama, sehingga waktu pembelajaran kurang. Proses pembentukan kelompok juga menjadi perhatian guru, agar memaksimalkan kerja dalam kelompok.

Refleksi

Dalam pembelajaran, siswa diajak bermain peran tokoh-tokoh sejarah. Permainan dilakukan dalam kelompok, menyesuaikan dengan karakteristik siswa kelas yang suka bermain dalam kelompok. Proses pembagian kelompok disini ternyata juga memerlukan perhatian khusus, karena pembagian kelompok yang kurang tepat akan membuat kinerja kelompok tersebut tidak optimal. Maka, guru perlu menggunakan beberapa cara pembagian kelompok yang membuat siswa menjadi nyaman dalam kelompoknya. Pembelajaran dengan menggunakan metode role playing pada siklus I membuat alokasi waktu atau jam pelajaran kurang. Waktu terasa berlalu begitu cepat, karena siswa asyik melakukan bermain peran. 
Hasil belajar IPS pada siklus I walapupun sudah terjadi peningkatan, namun masih dinilai kurang optimal.. Oleh karena itu, penelitian dilanjutkan ke siklus II dengan harapan dihasilkan hasil yang lebih baik.

\section{Siklus II}

Data yang diperoleh pada siklus I dijadikan sebagai acuan dalam pelaksanaan tindakan pada siklus II dengan yang mepituti kegiatan:

Perencanaan

Peneliti menyusun rencana tindakan yang sama dengan siklus I Pelaksanaan

Pelaksanaan penelitian siklus II dilaksanakan dalam tiga pertemuan, dengan tema lingkungan. Pembelajaran menggunakan metode pembelajaran role playing. Adapun nilai yang diperoleh siswa pada pra tindakan dapat disajikan dalam Tabel 3.

\section{Tabel 3}

Nilai Siswa Siklus II

\begin{tabular}{|c|l|c|c|}
\hline No & \multicolumn{1}{|c|}{ Kategori } & Jumlah & $(\%)$ \\
\hline 1 & Siswa yang tuntas & 40 & 95 \\
\hline 2 & Siswa yang tidak tuntas & 2 & 5 \\
\hline 3 & Rata-rata nilai & 85,1 & \\
\hline 4 & Ketuntasan kelompok & \multicolumn{2}{|c|}{$95 \%$} \\
\hline
\end{tabular}

Observasi

Kegiatan pembelajaran pada siklus II berlangsung dengan menyenangkan. Siswa aktif mengikuti setiap kegiatan dalam pembelajaran, sering bertanya dan mampu menjawab pertanyaan yang disampaikan guru. Kegiatan belajar tidak lagi berpusat pada guru, tapi pada siswa. Kekurangan waktu saat pembelajaran dengan menggunakan metode role playing dapat diatasi dengan membatasi waktu, sehingga pembelajaran dapat berlangsung efektif dan efisien.

Refleksi

Penggunaan metode role playing pada siklus II sudah cukup efektif, proses pembelajaran menjadi menyenangkan, siswa ikut berpartisipasi aktif dalam pembelajaran dan dapat meningkatkan hasil belajar IPS. Namun, di sisi lain masih perlu dilakukan seperti, pembagian kelompok dengan tepat, 
penentuan metode yang akan dilakukan harus disesuaikan dengan indikator, penyampaian aturan diperjelas, manajemen waktu pelaksanaan dan kreatif guru dalam mengarahkan kegiatan pembelajaran dari awal sampai akhir agar sesuai dengan rencana yang telah dibuat.

Persentase pencapaian KKM meningkat pada setiap tindakan yang dilakukan dan sudah melampaui target persentase pencapaian $\mathrm{KKM} \geq 80 \%$. Karenanya, tidak perlu dilanjutkan pada siklus III. Gambar 3. Menampilkan diagram peningkatan nilai rata-rata pada setiap tindakan.

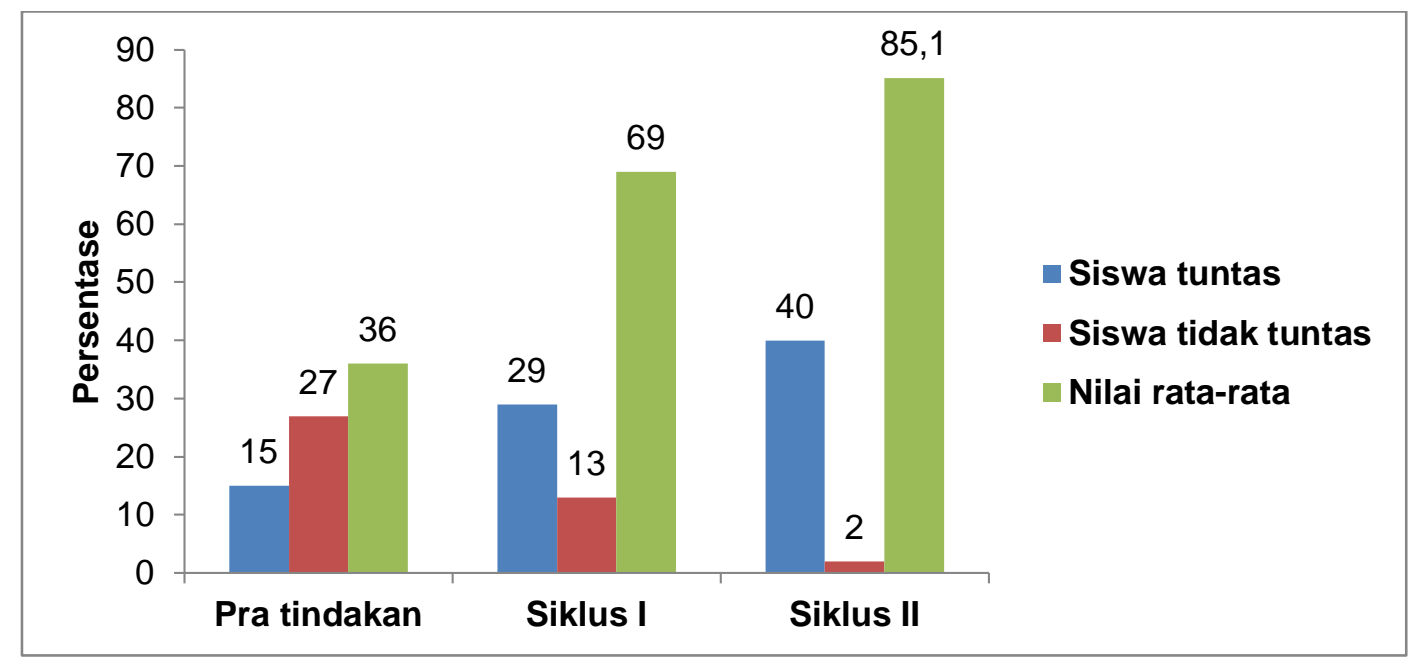

\section{Gambar 1 \\ Diagram peningkatan nilai rata-rata pada setiap tindakan}

Gambar 3 tersebut memberikaninformasi bahwa dengan menerapkan metode pembelajaran role playing, hasil belajar IPS siswa kelas VIII.D SMP Negeri 40 Pekanbaru dapat meningkatkan secara bertahap dan signifikan.

\section{SIMPULAN}

Penerapan metode pembelajaran role playing telah meningkatkan hasil belajar IPS siswa kelas VIII.D SMP Negeri 40 Pekanbaru tahun 2017 dengan nilai rata-rata kelas dan persentase pencapaian KKM pada saat pra penelitian adalah 69,3 dan $36 \%$, pada siklus I menjadi 78,6 dan $69 \%$, serta pada siklus II menjadi 85,1 dan $95 \%$.

\section{DAFTAR PUSTAKA}


Anas, Sudijono. 2011. Pengantar Evaluasi Pendidikan. Jakarta: Raja Grafindo Persada.

Arikunto, Suharsimi. 2013. Dasar-Dasar Evaluasi Pendidikan. Jakarta: PT Bumi Aksara.

Hanafiah, Nanang dan Cucu Suhana. 2010. Konsep Strategi Pembelajaran. Bandung: Refika Aditama.

Hamalik, Oemar. 2012. Proses Belajar Mengajar. Jakarta: PT Bumi Aksara.

Muslich, Masnur. 2008. KTSP Pembelajaran Berbasis Kompetensi dan Kontekstual. Jakarta: Bumi Aksara.

Prayitno, Edi dan Sri Wulandari. 2014. Evaluasi Hasil Penelitian. Yogyakarta: Pustaka Pelajar.

Purwanto, N. 2012. Prinsip-Prinsip dan Teknik Evaluasi Pembelajaran. Bandung: Remaja Rosda Karya.

Rusman. 2012. Model-Model Pembelajaran Mengembangkan Profesionalisme Guru. Jakarta: PT Raja Grafindo Persada.

Sanjaya, Wina. 2011. Strategi Pembelajaran Berorientasi Standar Proses Pendidikan. Jakarta: Kencana Prenada Media.

Sudjana, Nana. 2012. Penilaian Hasil Proses Belajar Mengajar. Bandung: Remaja Rosdakarya.

Susilawati dan Ita Rustati. 2013. Pembelajaran dan Evaluasi Hasil Belajar IPS. Bandung: UPI Press.

Thobroni, M. 2015. Belajar dan Pembelajaran: Teori dan Praktik. Yogyakarta: Arruzz Media. 